\title{
Sea drowning: a case report and review of the literature
}

\author{
A. Estella A, L. Pérez Bello Fontaiña
}

\begin{abstract}
Sea Drowning: a case report and review of the literature. A. Estella A, L. Pérez Bello Fontaiña.

400,000 incidents of sea drowning take place every year. We report the case of a woman, 34 years old, attended on the beach by external hospital emergency services after suffering immersion in seawater resulting in drowning due to acute respiratory failure. She was admitted to the critical
\end{abstract}

Intensive Care Unit, Hospital of Jerez, Jerez de la Frontera (Cádiz), Spain.

Correspondence: Angel Estella, Intensive Care Unit. Hospital of Jerez, Carretera Cadiz s/n. CP: 11407 Jerez de la Frontera (Cádiz), Spain; e-mail: litoestella@hotmail.com

\section{Introduction}

According to World Health Organisation estimates, nearly 400,000 incidents of sea drowning take place each year [1]. Although these can often be prevented, in Spain around one hundred such deaths are recorded annually. The physiopathological mechanism involved is hypoxia, which is why prompt cardiopulmonary resuscitation manoeuvres and actions taken to improve ventilation are crucial to the outcome of these patients. The following is a case in which emergency fiberoptic bronchoscopy was performed, extracting a large quantity of sand and algae, following which both pulmonary mechanic measurements and hypoxia improved.

\section{Case Report}

A woman, 34 years old, with no relevant medical history, attended on the beach by external hospital emergency services after suffering immersion in seawater resulting in drowning due to acute respiratory failure. The patient was connected to a mechanical ventilator and oro-tracheal intubation and cardiopulmonary resuscitation were successfully performed; following this she was taken to hospital and admitted to the emergency department.

Upon arrival at the emergency department she presented an arterial oxygen saturation of $82 \%$, in spite of $\mathrm{FiO}_{2}$ requirements of 1.0. Arterial pressure was $125 / 65 \mathrm{mmHg}$, cardiac frequency: 120 beats per minute and temperature $34.5^{\circ} \mathrm{C}$.

Preliminary diagnostic tests revealed venous gas analysis with a $\mathrm{pH}$ of $6.9, \mathrm{pCO}_{2} 32 \mathrm{mmHg}$, $\mathrm{HCO}_{3}: 7 \mathrm{mEq} / \mathrm{l}$, lactic acid $3.6 \mathrm{mOsm} / \mathrm{l}$. Biochemistry revealed $\mathrm{Na}: 150 \mathrm{mEq} / \mathrm{l}, \mathrm{K}: 2,3 \mathrm{mEq} / \mathrm{l}$.
The chest x-ray showed normal cardiac silhouette and bilateral alveolar-interstitial infiltrates.

Upon admission mechanical pulmonary ventilation was performed, during which high peak pressure, plateau pressure of $25 \mathrm{~cm} \mathrm{H}_{2} \mathrm{O}$ with a compliance of $30 \mathrm{ml} / \mathrm{cm} \mathrm{H}_{2} \mathrm{O}$ and resistance of 20 $\mathrm{cm} \mathrm{H}_{2} \mathrm{O} / \mathrm{l} / \mathrm{sec}$ were observed.

Mechanical ventilation mode was changed to pressure control, improving arterial blood gas analysis, and an emergency fiberoptic bronchoscopy was performed, as a result of which an oedema of the bronchial mucosa was observed, together with abundant deposits of sand and algae along the bronchial tree, a great quantity of which was extracted through the channel of the bronchoscope (figure 1). Samples were sent for microbiological analysis and empirical antibiotic treatment was initiated with intravenous meropenem.

After the fiberoptic bronchoscopy, respiratory function improved and a decrease in peak pressure was observed together with improved compliance, as a result of which $\mathrm{FiO}_{2}$ requirements were gradually reduced.

Hemodynamic monitoring using oesophageal echo-Doppler was performed, obtaining a cardiac output of $4.3 \mathrm{~L} / \mathrm{min}$ and data suggesting preload dependency, initiating increased volume, which resulted in cardiac output increasing to $5.8 \mathrm{~L} / \mathrm{min}$.

Four hours after admission sedation was removed in order to perform a neurological test, which showed the patient was able to obey simple instructions and move all 4 extremities.

Twenty four hours after admission a cranial CT scan showing occupation of sphenoid sinuses and mastoid cells was performed, and a multi-slice thoracic CT scan, which revealed multiple bilateral condensation areas and "ground glass opacity", more significant in posterior basal and left lung 


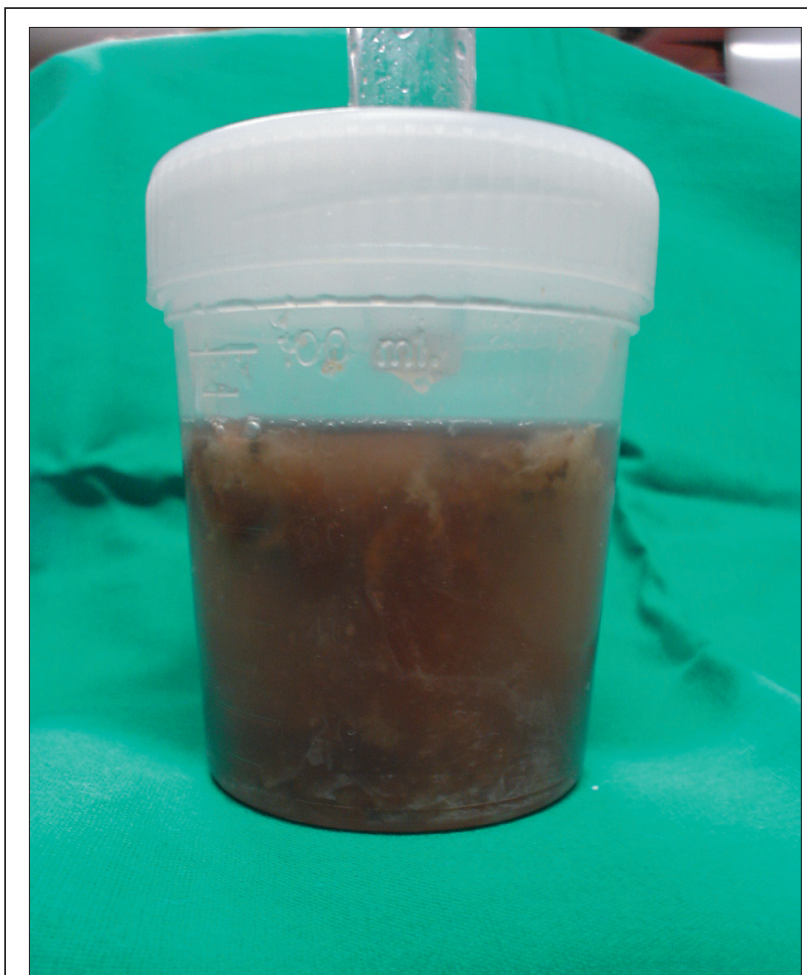

Fig. 1. - Bronchoscopic BAL obtained at the time of admission to the ICU.

segments, consistent with respiratory distress syndrome (figure 2).

After 8 days of mechanical ventilation the patient was extubated, with good clinical tolerance; the radiological infiltrate detected at the time of admission gradually improved in the subsequent chest x-rays performed (figure 3 ). The results of the microbiology cultures of the BAL were Streptococo mitis I, Coagulase-negative stafilococo, Corinebacterium species and Neisseria species.

ICU length of stay was 12 days. The patient was transferred to a ward in good clinical condition and with no neurological disturbances. Four days later, the patient remained asymptomatic and was discharged from the hospital. In a follow up visit after three months in the outpatient pulmonary consultation the patient was recovered without major problems.

\section{Discussion}

There are many cases of fatal drowning each year; according to estimates, around half a million incidents are recorded worldwide, and this figure is considered conservative. Drowning is the third cause of accidental death in the USA $[2,3]$. In literature there is a notable lack of agreement in the use of the terms drowning and near drowning: in a review of existing literature nearly 13 different definitions of near drowning were documented by Papa et al [4]. In order to standardise criteria on this terminology a consensus conference was held in 2002 during which it was agreed to define drowning as the process of experiencing respiratory impairment from submersion/immersion in liquid, irrespective of survival. The term near drowning is con- fusing and imprecise and should be abandoned; in spite of this, it is still in use [5,6]. Alterations in gas exchange, hypoxemia and deteriorated pulmonary compliance are the physiopathological mechanisms described in the initial stages in drowning patients [7-9]. In the case discussed here hypoxemia was significant, in spite of $\mathrm{FiO}_{2}$ of 1 and low compliance at the time of admission. In contrast to experimental models in which hemolysis, hyperkalemia and ventricular fibrillation are described, in humans the main causes of death by drowning are acidosis and hypoxemia. This difference can be explained by the fact that in experimental models much greater quantities of liquid are instilled into the lungs than would be the case in human drowning $[9,10]$. In the case discussed in this paper, the alterations observed could be a consequence of the presence of sea water, sand and algae in the alveolar space, with the corresponding destruction of the pulmonary surfactant and alteration of gas exchange; at the time of admission to the ICU a significant loss of pulmonary movement, hypoxemia and acidosis were observed. The hypokalemia described at the time of admission has been documented in half of the 31 cases described by Oehmichen et al [9]. Hemodynamic monitoring data from this case revealed hypovolemia, and preliminary analyses showed hypernatremia; these alterations were described in sea water immersion by Swann et al [11]. Some studies suggest that cardiovascular changes are secondary to hypoxia $[12,13]$. Pulmonary oedema is a commonly described complication; the findings of the chest $\mathrm{x}$-ray, together with hypoxemia, suggested treatment with diuretics, although the hamodynamic situation and volemia of these patients is noteworthy, and these were monitored obtaining data consistent with preload dependency, initiating increased volume which resulted in increased cardiac output [14]. Of course, prompt treatment to minimise the period of hypoxia and neurological disturbances are the main therapeutic objective, and in the case discussed here oro-tracheal intubation and advanced cardiopulmonary resuscitation manoeuvers were immediately initiated and the patient was rushed to hospital [15]. Antibiotic

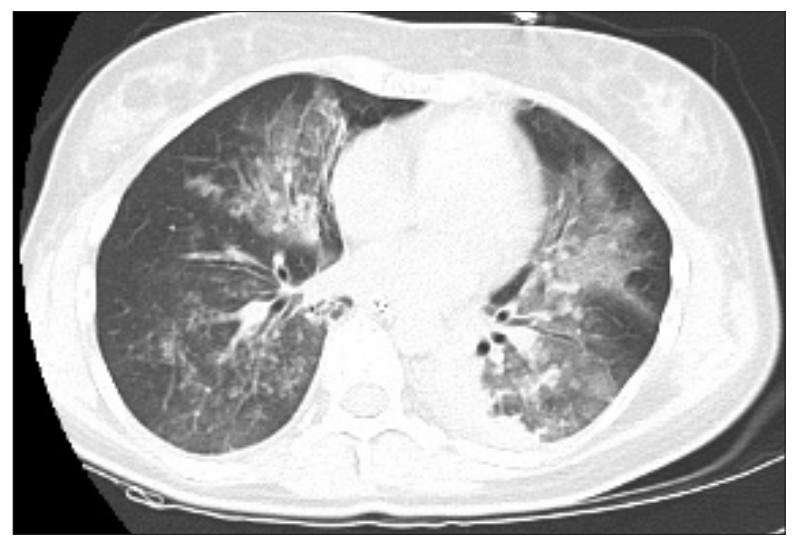

Fig. 2. - Thoracic CT. 


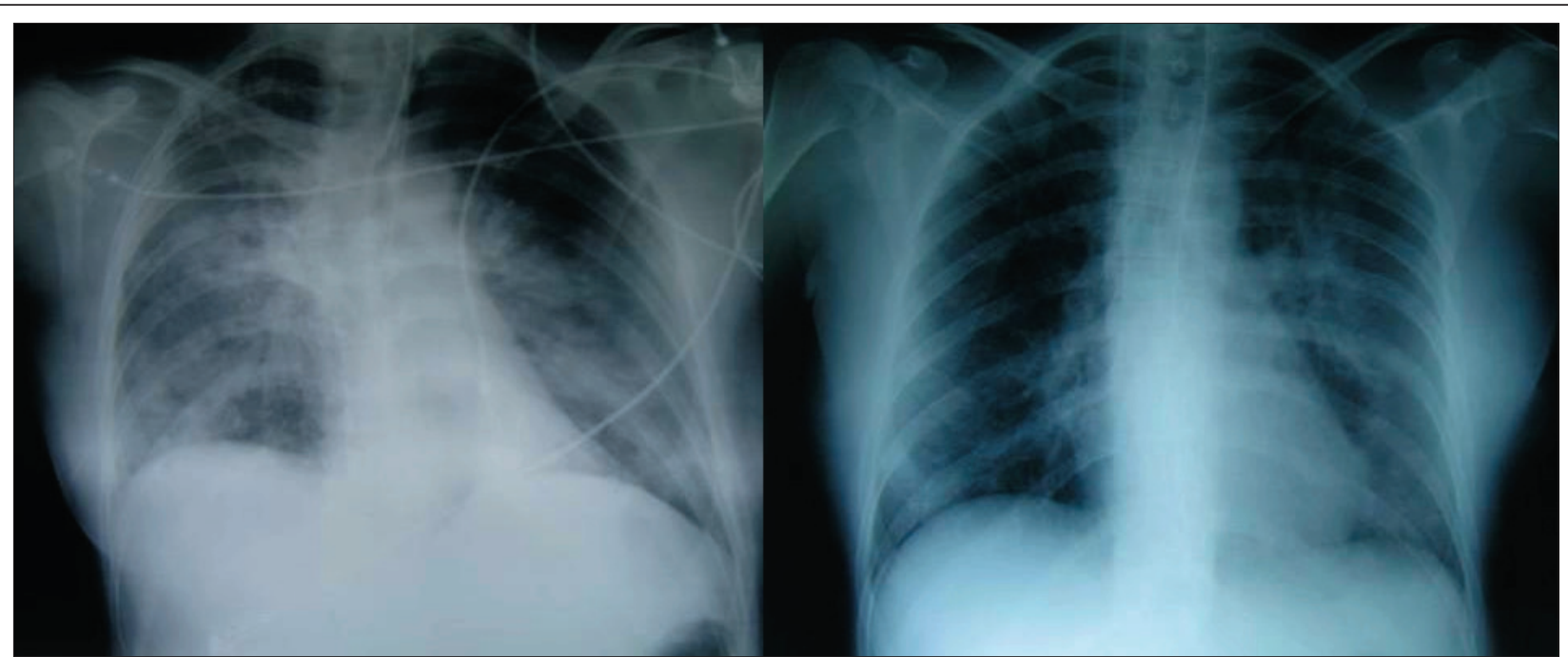

Fig. 3. - Chest radiographs on admission and 12 days later on discharge from the ICU.

treatment is not initially required unless the matter collected from the bronchial tree is very contaminated [15]. The BAL performed revealed abundant, thick secretions and remains of algae and sand, which prompted us to initiate empirical antibiotic treatment with meropenem; the subsequent microbiological analysis confirmed a polymicrobial infection. At the time of admission the patient had a temperature of $34.5^{\circ} \mathrm{C}$; hypothermia could have helped protect cerebral function as it reduces the brain's demand for oxygen. In the case discussed here, prompt orotracheal intubation, connection to mechanical ventilation, cardiopulmonary resuscitation manoeuvers and transfer to hospital, together with hypothermia, are described as being associated with improved outcome in this kind of patient; however, few publication describe prompt fibrobronchoscopy to extract inhaled matter.

Not many cases documenting the use of bronchoscopy in sea drowning are found in literature; only a few case reports have been published, frequently involving children $[16,17]$.

In our experience, mechanical pulmonary measurements improved after BAL, and immediately, following this, $\mathrm{O}_{2}$ saturation increased, and $\mathrm{FiO}_{2}$ requirements were reduced. In this case emergency fiberoptic bronchoscopy was not only useful for extracting matter but also contributed towards the microbiological diagnosis of pneumonia.

\section{References}

1. World Health Organization. The World Health Report, 2002: Reducing risks, promoting healthy life, Geneva. World Health Organization, 2002.
2. De Nicola LK, Falk JL, Swanson ME, et al. Submersion injuries in children and adults. Crit Care Clin 1997; 13: 477-502.

3. Sachdeva, RC. Near drowning. Crit Care Clin 1999; 15: 281.

4. Papa L, Hoelle R, Idris A. Systematic review of definitions for drowning incidents. Resuscitation 2005; 65: 255-264.

5. Idris AH, Berg RA, Bierens $\mathrm{J}$, et al. Recommended guidelines for uniform reporting of data from drowning: the "Utstein style". Resuscitation 2003; 59: 45-57.

6. Uchiyama N, Suda R, Yamao S, et al. Organising pneumonia alter near-drowning. BMJ Case Reports 2009 [doi:10.1136/bcr.02.2009.1557]

7. Orlowski JP, Abulleil MM, Phillips JM. Effects of tonicities of saline solutions on pulmonary injury in drowning. Crit Care Med 1987; 15: 126-130.

8. Van Berkel M, Bierens JJLM, Lie RLK, et al. Pulmonary edema, pneumonia and mortality in submersions victims. A retrospective study in 125 patients. Intensive Care Med 1996; 22: 101-107.

9. Oehmichen M, Hennig R, Meissner C. Near-drowning and clinical laboratory changes. Legal Medicine 2008; 10: 1-5.

10. Fuller R. Drowning and the post-inmersion syndrome: a clinicopathologic study. Mil Med 1963; 128: 22.

11. Swann HG, Spallford NR. Body salt and water changes during fresh water and sea water drowning. Tex Rep Biol Med 1951; 9: 356-382.

12. Modell JH. Serum electrolyte changes in near-drowning victims. JAMA 1985; 253: 557.

13. Bierens JJ, Knape JT, Gelissen HP. Drowning. Curr Opin Crit Care 2002; 8: 578-86.

14. Salomez F, Vincent JL. Drowning: a review of epidemiology, pathophysiology, treatment and prevention. Resucitation 2004; 63: 261-268.

15. Modell JH. Drowning. N Eng J Med 1993; 328: 253-6.

16. Kapur N, Slater A, McEniery J, Greer ML, Masters IB, Chang AB. Therapeutic bronchoscopy in a child with sand aspiration and respiratory failure from near drowning - case report and literature review. Pediatr Pulmonol 2009; 10: 1043-7.

17. Choy IO, Idowu O. Sand aspiration: a case report. $J P e-$ diatr Surg 1996; 10: 1448-50. 